\title{
Morphology and Properties of Geopolymer Coatings on Glass Fibre-Reinforced Epoxy (GRE) pipe
}

\author{
Noor Fifinatasha Shahedan, ${ }^{1, *}$, Mohd Mustafa Al Bakri Abdullah ${ }^{1}$, Che Mohd Ruzaidi \\ Ghazali $^{2}$, Mohammed Binhussain ${ }^{3}$, Mohammed Al Husaini ${ }^{3}$, Kamarudin Hussin ${ }^{2}$ and \\ Shamala Ramasamy ${ }^{1}$ \\ ${ }^{1}$ Center of Excellence Geopolymer and Green Technology (CEGeoGTech), School of Materials \\ Engineering, Universiti Malaysia Perlis (UniMAP), 01007, P.O Box 77, D/A Pejabat Pos Besar, \\ Kangar, Perlis, Malaysia. \\ ${ }^{2}$ Faculty of Engineering Technology, Universiti Malaysia Perlis (UniMAP), P.O. Box 77, D/A \\ Pejabat Pos Besar, Kangar, Perlis 01000, Malaysia. \\ ${ }^{3}$ King Abdul Aziz City Science \& Technology (KACST), P.O. Box Riyadh 11442, Kingdom of Saudi \\ Arabia.
}

\begin{abstract}
Geopolymer coatings were coated on glass fibre-reinforced epoxy (GRE) pipe by using kaolin, white clay and silica sand as source materials and sodium hydroxide $(\mathrm{NaOH})$ and sodium silicate $(\mathrm{Na} 2 \mathrm{SiO} 3)$ as alkaline solution. The microstructure and mechanical property of geopolymer coating on GRE pipe were methodically investigated through morphology analysis, and flexural strength test. The result indicates the microstructure and interfacial layer between geopolymer coating and GRE pipe significantly influence the mechanical property of geopolymer coating. However, different source materials gave different microstructure and property in geopolymer coating.
\end{abstract}

\section{Introduction}

Geopolymer has received much attention as green alternative to ordinary Portland cement (OPC), with most of the work focused on broad applications in transportation, emergency repairs, metallurgy, coating, membrane materials and nuclear waste disposal [1-5]. The workability of geopolymer and manufactured at normal temperature has made geopolymer increasingly being used in fireproofing covers, mending interfaces, coating pipelines and floors, and as adhesives [6, 7]. Geopolymer has displayed an opportunity all together to improve both environmental and engineering performance compared to traditional technology $[8,9]$. Due to the excellent resistance to sulphate and seawater attack $[10,11]$, geopolymer as a novel coating material has been studied for protective marine concretes $[12,13]$. Geopolymer coating application has been studied to advance the performance in aircraft [14], construction [15]. Besides, geopolymer have properties of anti-aging and anti-

\footnotetext{
*Corresponding author: sfifinatasha@yahoo.com
} 
ultraviolet capability that make geopolymer suitable for fabricating inorganic exterior wall building coating $[16,17]$.

In geopolymer coating, geopolymer source material used as aluminosilicate source to produce geopolymer coating material by using sodium hydroxide $(\mathrm{NaOH})$ and sodium silicate $\left(\mathrm{Na}_{2} \mathrm{SiO}_{3}\right)$ as alkaline activator [18-21]. Geopolymer source materials such as fly ash, kaolin, silica fume, ground granulate blast slag (GGBS), boiler ash and volcano ash reactivated via alkaline solution has potential to be use as geopolymer coating. Previous research in geopolymer studied has proved that fly ash was possesses good quality mechanical properties and durability in aggressive environments [19] while silica fume has been research as one of the source materials by adding the silica fume content and test based on the geopolymer porosity, water absorption and strength [22]. Besides that, kaolin as source material in geopolymer has improved mechanical strength [23]. According to the past research, GGBS activated with alkaline solution can be used to make slag concrete with satisfactory workability and strength properties [24].

Hence, these geopolymer coating can be one of the solution to reduce the risk or lack of workability such as on glass fibre-reinforced epoxy (GRE). As the use of these material increases, so does the need to define reliable design limits in terms of performance. Most important arguably, is to predict the long term behaviour of these pipes (20-30 years) under complex loading based on the data recorded from short term failure tests. GRE pipes are normally designed to withstand high pressure. However, as with all pipelines, GRE pipes face significant risks of external interference of pipeline failures and has to spend millions of money in maintenance. Therefore, by applying geopolymer coating it can improvise the mechanical and physical properties of the GRE pipe based industrial needed. The potential of source materials geopolymer such as kaolin, white clay and silica sand has been study for the synthesis of geopolymer in geopolymer coating application.

\section{Experimental Setup}

Kaolin, white clay and silica sand from Saudi Arabia have been used as raw materials in geopolymer coating paste. Raw materials sample is sieved at $100 \mu \mathrm{m}$.

For alkaline activator solution, sodium hydroxide $(\mathrm{NaOH})$ and sodium silicate (Na2SiO3) was prepared according to the Table $1 . \mathrm{NaOH}$ in pellet from with $(99 \%)$ purity and $\mathrm{Na} 2 \mathrm{SiO} 3$ consists of $\mathrm{Na} 2 \mathrm{O}=14.7 \%, \mathrm{SiO} 2=29.4 \%$ and $\mathrm{H} 2 \mathrm{O}=55.9 \%$.

\subsection{Sample preparation}

Geopolymer coating paste was prepared by mixing aluminosilicate source materials with alkaline activator solution. Kaolin, white clay and silica sand from Saudi Arabia act as aluminosilicate source materials has been sieved at $100 \mu \mathrm{m}$ in this study. Chemical composition of kaolin, white clay and silica sand as measured by XRF is as follows (Table 1). Dissolution of sodium hydroxide $(\mathrm{NaOH})$ one litre of distilled water in a volumetric flask to obtain a $8 \mathrm{M}$ concentration of $\mathrm{NaOH}$. The ratio of solid/liquid in geopolymer coating paste was fixed at 1.0 [25] for all mixtures with various $\mathrm{Na}_{2} \mathrm{SiO}_{3} / \mathrm{NaOH}$ ratio is studied. Sodium hydroxide $(\mathrm{NaOH})$ and sodium silicate $\left(\mathrm{Na}_{2} \mathrm{SiO}_{3}\right)$ as alkaline activator was mixed together just before it was mixed with the aluminosilicate source materials which were kaolin and white clay. After that, the alkaline solution was added to kaolin powder and mixed for $2-5$ minutes to get homogenous mixture. The same step was conducting to the white clay and silica sand powder. Geopolymer coating paste then was applied to the GRE pipe by brushing method. Thickness of coating varied between $0.3-0.5 \mathrm{~mm}$. Then 
sample GRE pipe that has been coated is placed at $75^{\circ} \mathrm{C}$ in the oven for 48 hours. Surface treatment is applied on the GRE pipe sample before coated with geopolymer. GRE pipe sample has been cut with dimension $2.5 \mathrm{~cm} \times 8 \mathrm{~cm}$ was cleaned with abrasive paper (grade 80 ) then washed with detergent, distilled water and methyl ethyl katone (MEK).

Table 1. The chemical composition raw materials of kaolin, white clay and silica sand from

\begin{tabular}{|c|c|c|c|}
\hline $\begin{array}{c}\text { Chemical } \\
\text { Composition }\end{array}$ & $\begin{array}{c}\text { Kaolin } \\
\mathbf{( \% )}\end{array}$ & $\begin{array}{c}\text { White Clay } \\
\mathbf{( \% )}\end{array}$ & $\begin{array}{c}\text { Silica Sand } \\
\text { (\%) }\end{array}$ \\
\hline $\mathrm{SiO}_{2}$ & 50.8 & 50.8 & 97.39 \\
\hline $\mathrm{Al}_{2} \mathrm{O}_{3}$ & 39.3 & 39.7 & 1.88 \\
\hline $\mathrm{CaO}$ & 0.43 & 0.37 & 0.041 \\
\hline $\mathrm{Fe}_{2} \mathrm{O}_{3}$ & 2.21 & 2.13 & 0.090 \\
\hline $\mathrm{MgO}$ & 0.45 & 0.40 & 0.41 \\
\hline $\mathrm{ZrO}_{2}$ & 0.69 & 0.57 & 0.0459 \\
\hline $\mathrm{TiO}_{2}$ & 5.73 & 5.6 & 0.090 \\
\hline $\mathrm{K}_{2} \mathrm{O}$ & 0.06 & 0.05 & 0.027 \\
\hline $\mathrm{V}_{2} \mathrm{O}_{5}$ & 0.11 & 0.11 & 0.001 \\
\hline
\end{tabular}

\section{Mechanical Property of Coating}

\subsection{Flexural Strength}

Flexural strength is important to GRE pipe to overcome the significant risks of external interference of pipeline failures in the ground level based on industrial needed and how it improved with the applied of geopolymer coating. The result stated the highest flexural strength of kaolin, white clay and silica sand geopolymer coating sample was at $0.40-0.60$ ratio of $\mathrm{Na}_{2} \mathrm{SiO}_{3} / \mathrm{NaOH}$ as shown in Figure 1. The coated GRE pipe sample with geopolymer coating has significantly improved the result of flexural strength up to $60 \%$ compare to control sample (without coating) which was $18.57 \mathrm{MPa}$ to the same conditions. The $\mathrm{Na}_{2} \mathrm{SiO}_{3} / \mathrm{NaOH}$ ratio was importance for the geopolymerization process and acted as alkaline activator, binder and plasticizer or dispersant [26]. Previous study $\mathrm{Na}_{2} \mathrm{SiO}_{3} / \mathrm{NaOH}$ ratios affected the workability of the kaolin geopolymer [25]. The workability of the kaolin geopolymer mixes decreased with increasing in the ratios. 


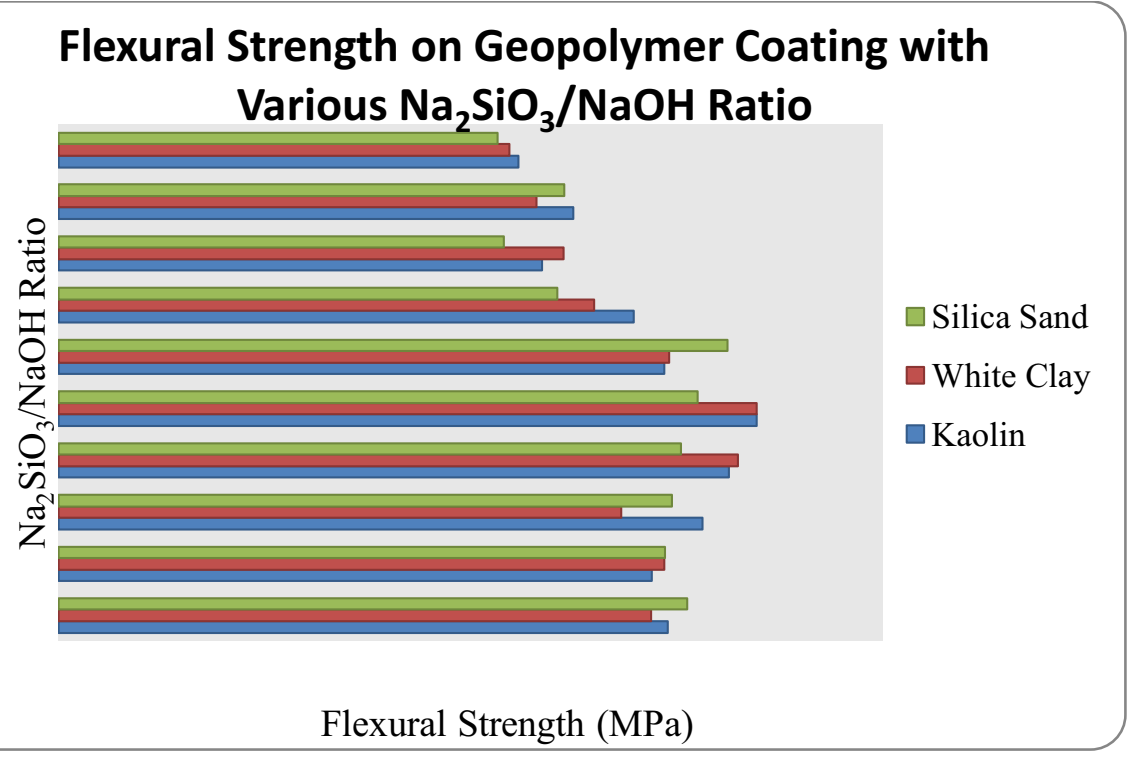

Fig. 1. Effect of $\mathrm{Na}_{2} \mathrm{SiO}_{3} / \mathrm{NaOH}$ ratio to flexural strength in geopolymer coating formulation

\section{Morphology Analysis}

\subsection{Scanning electron microscopy}

The determination morphology characterization of kaolin, white clay and silica sand has been analyzed on raw materials and geopolymer coating paste. The sample is selected for the best flexural strength kaolin, white clay and silica sand geopolymer coating.

Scanning electron microscopy (SEM) image of raw materials kaolin and white clay demonstrated kaolinite particles of reveal irregular platelets that are arranged in face-to-face patterns as shown in Figure 2 (a) and Figure 3 (a). Pseudo hexagonal kaolinite and some rolled and rough edged kaolinite particles are also observed. The small platelets of submicron size of kaolin and white clay show less than $2 \mu \mathrm{m}$. According to the past research, the particle size in the coating application is mainly under $2 \mu \mathrm{m}$ which lead to the bigger surface for geopolymerization process [27]. However, the rounded corners and spherical quartz particle of different sizes appears in raw materials silica sand can be observed in Figure 4 (a). Kaolin, white clay and silica sand are suitable to be use as main sources materials in geopolymer coating application because of the particles with broken edges appear contributed to the increase of the total surface charge and the reaction during geopolymerization [28].

The microstructure of the best design all geopolymer coating shows the formation of large compacted area compare to the un-reacted particle. The SEM image analysis of kaolin and white clay based geopolymer coating (Figure 2 (b) and Figure 3 (b)) obviously shows the raw particles has been stimulated by the alkaline activator solution with alters at the edges of the plate-like particles and became more compact [28, 29]. The microstructure of silica sand based geopolymer coating showed more homogeneous structure with more intervening materials was examined (Figure 4 (b)). The form of compacted structure proved that the geopolymerization reaction occurred at almost all part of raw particle in silica sand. 


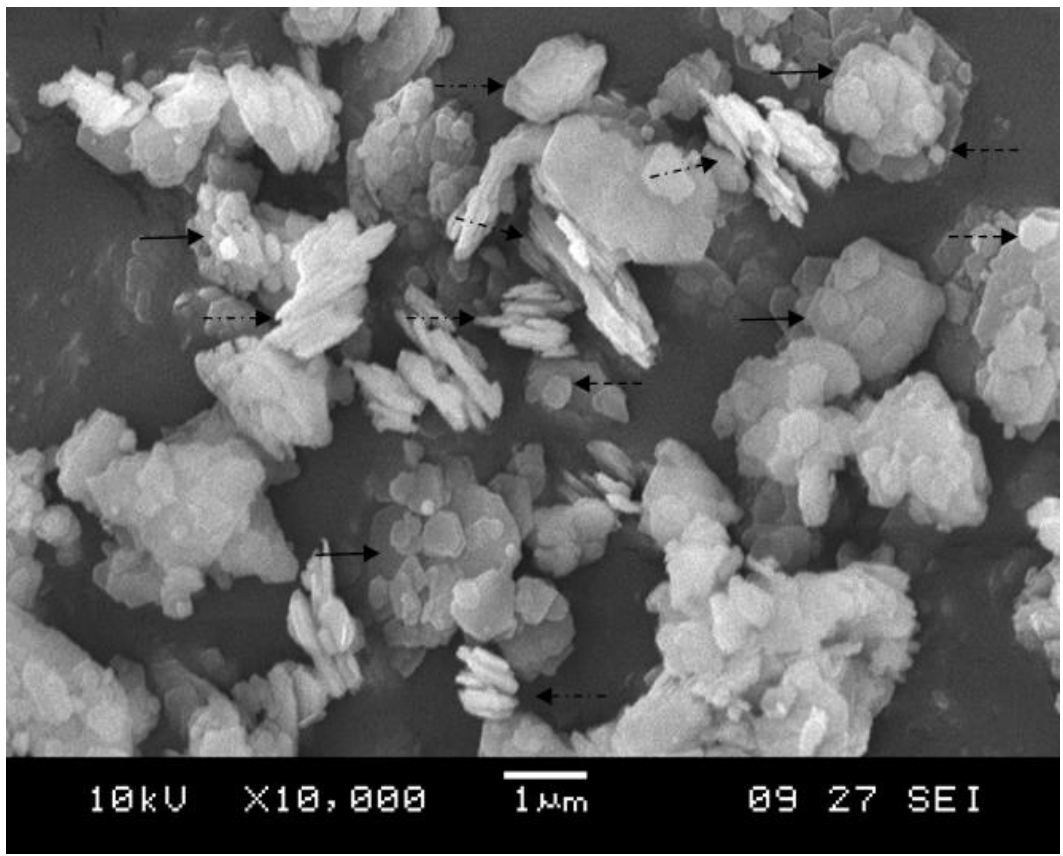

Fig. 2(a). SE image of the raw material kaolin: pseudo hexagonal kaolinite in face to face arrangement $(\rightarrow)$; rolled and rough edged kaolinite $(--\rightarrow)$; and booklets of kaolinite $(-\cdot \rightarrow)$

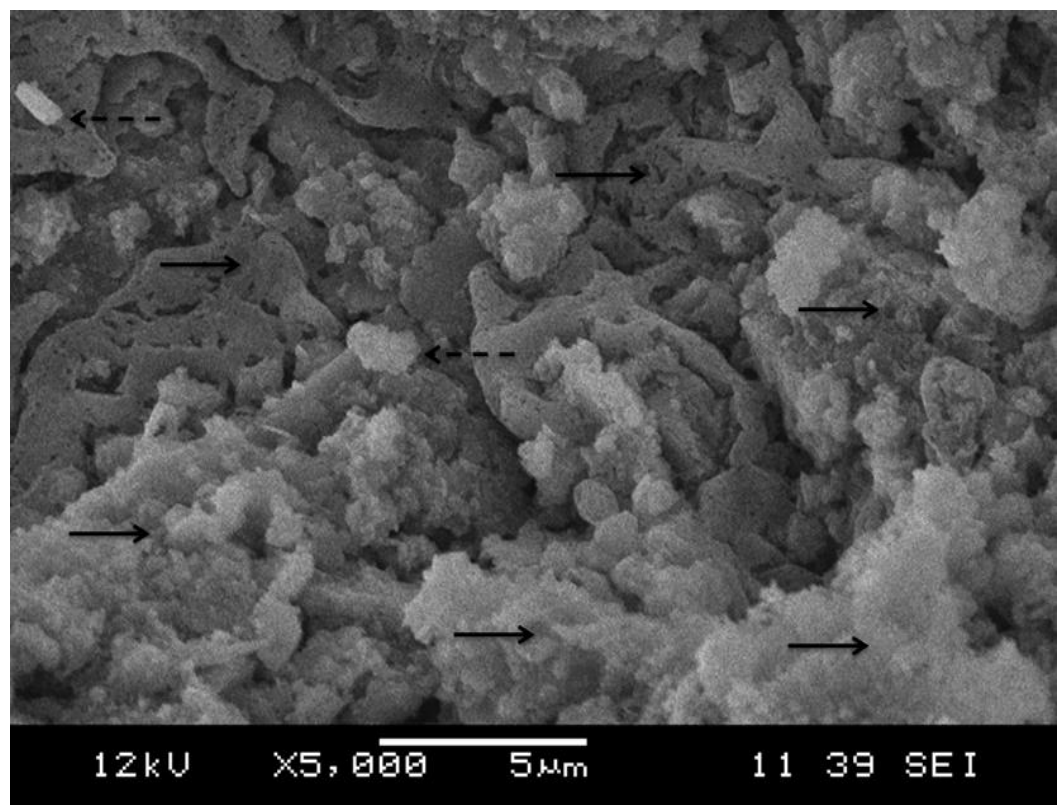

Fig. 2(b). SE image of the kaolin based geopolymer: compacted area $(\rightarrow)$; un-reacted particles $(--\rightarrow)$ 


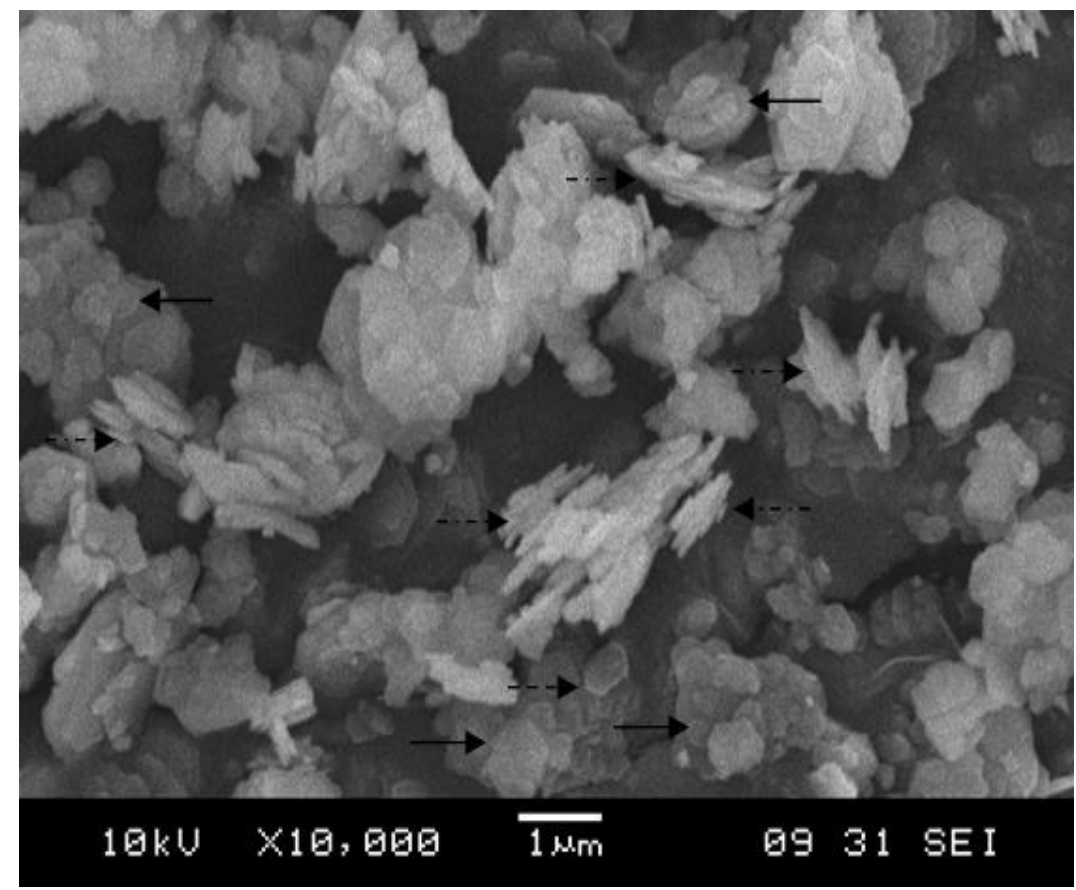

Fig. 3(a). SE image of the raw material white clay: pseudo hexagonal kaolinite in face to face arrangement $(\rightarrow)$; rolled and rough edged kaolinite $(---\rightarrow)$; and booklets of kaolinite $(-\cdots \rightarrow)$

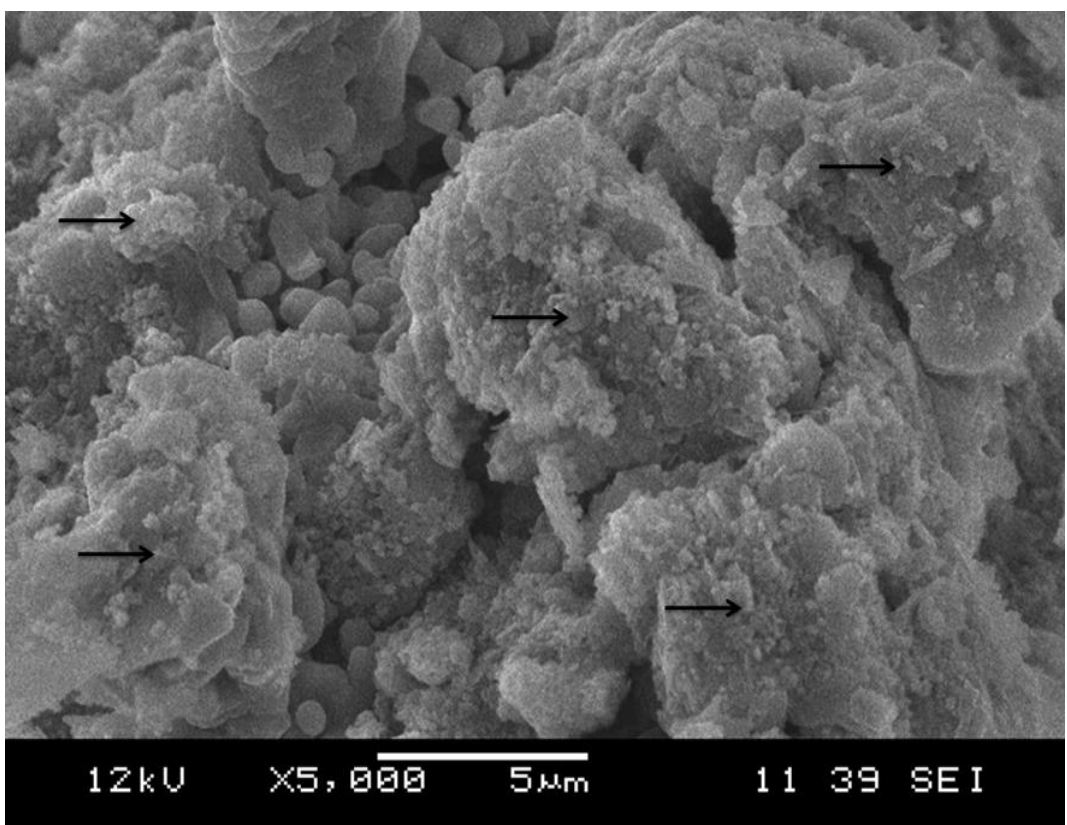

Fig. 3(b). SE image of the white clay based geopolymer: compacted area $(\rightarrow)$ 


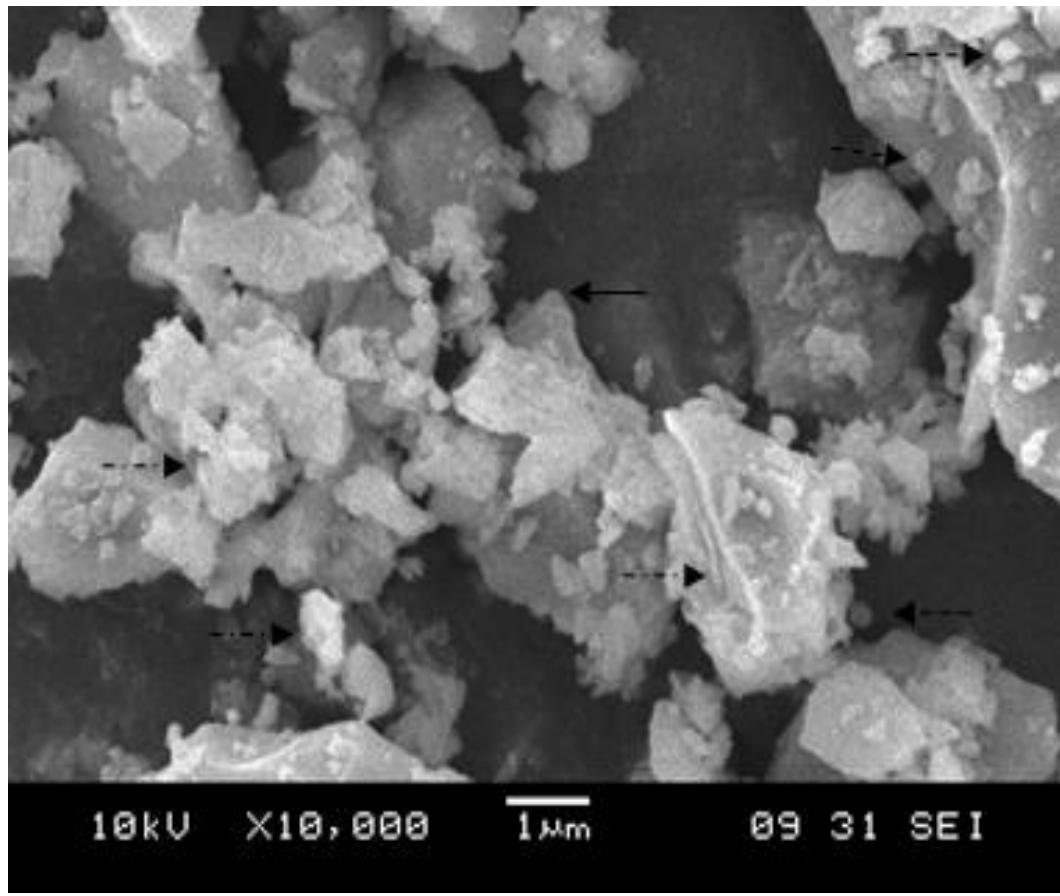

Fig. 4(a). SE image of the raw material silica fume: rounded corners $(\rightarrow)$; spherical quartz particle $(--\rightarrow)$; and stack $(-\cdots)$

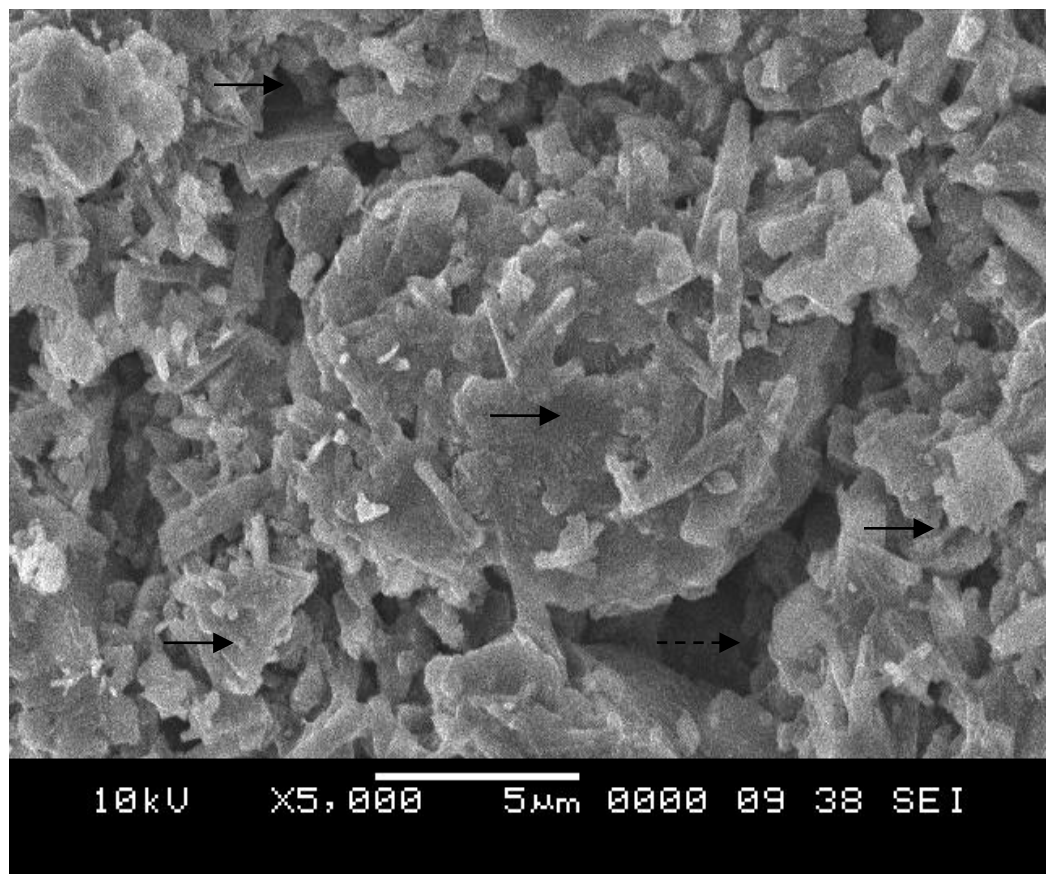

Fig. 4(b). SE image of the silica fume based geopolymer: compacted area $(\rightarrow)$ and pore area $(--\rightarrow)$ 


\subsection{Interfacial study on layer between geopolymer coating and GRE pipe}

The optical microscope is used in interfacial study to observe the GRE pipe sample with and without geopolymer coating. Figure 5 (a) is shows the GRE pipe sample without geopolymer coating after flexural strength testing. The interface between kaolin, white clay and silica sand geopolymer coating with the best strength in flexural and GRE pipe sample is observed under optical microscope to distinguish the different. The optical microscope image in Figure 5 (b) - (c) shows the damage and crack on GRE pipe sample is decreased compare to the GRE pipe sample without geopolymer coating. Davidovits [30] propose by varied the $\mathrm{Si} / \mathrm{Al}$ ratio, it is possible to regulate the properties of geopolymer performance. Therefore, the best mix design for geopolymer coating form rigid final product, improve mechanical properties and formed better interfacial in geopolymer coating.

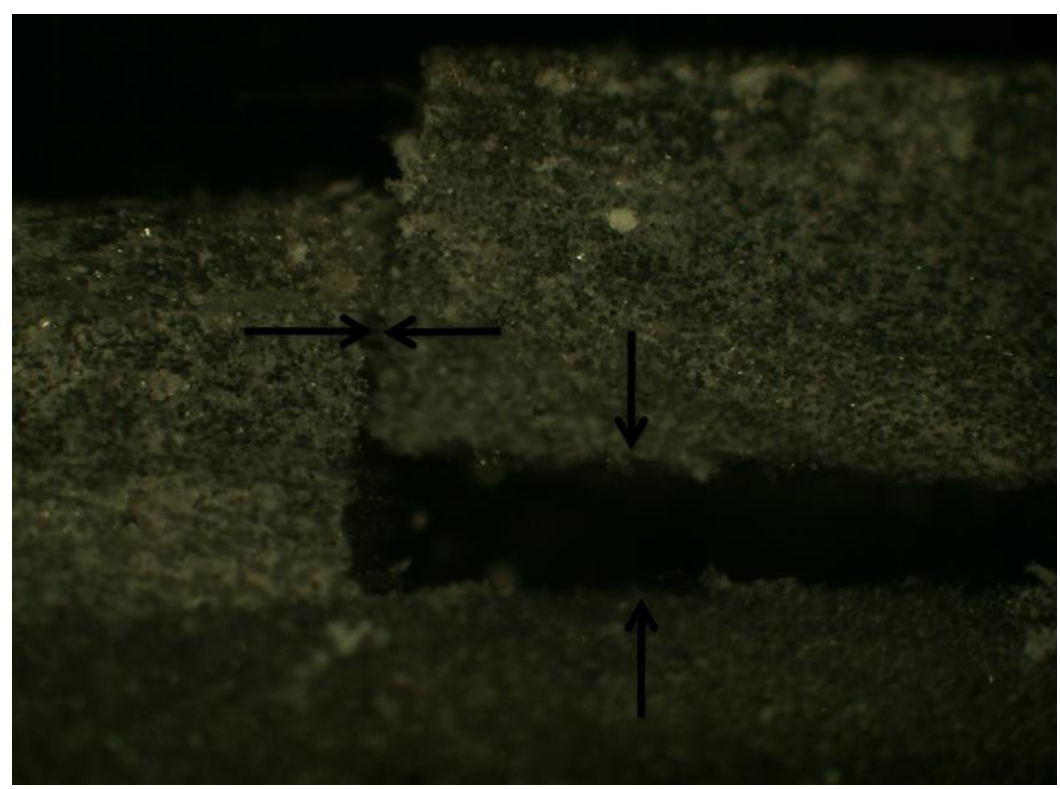

Fig. 5(a). The optical microscope image for GRE pipe sample after flexural testing 


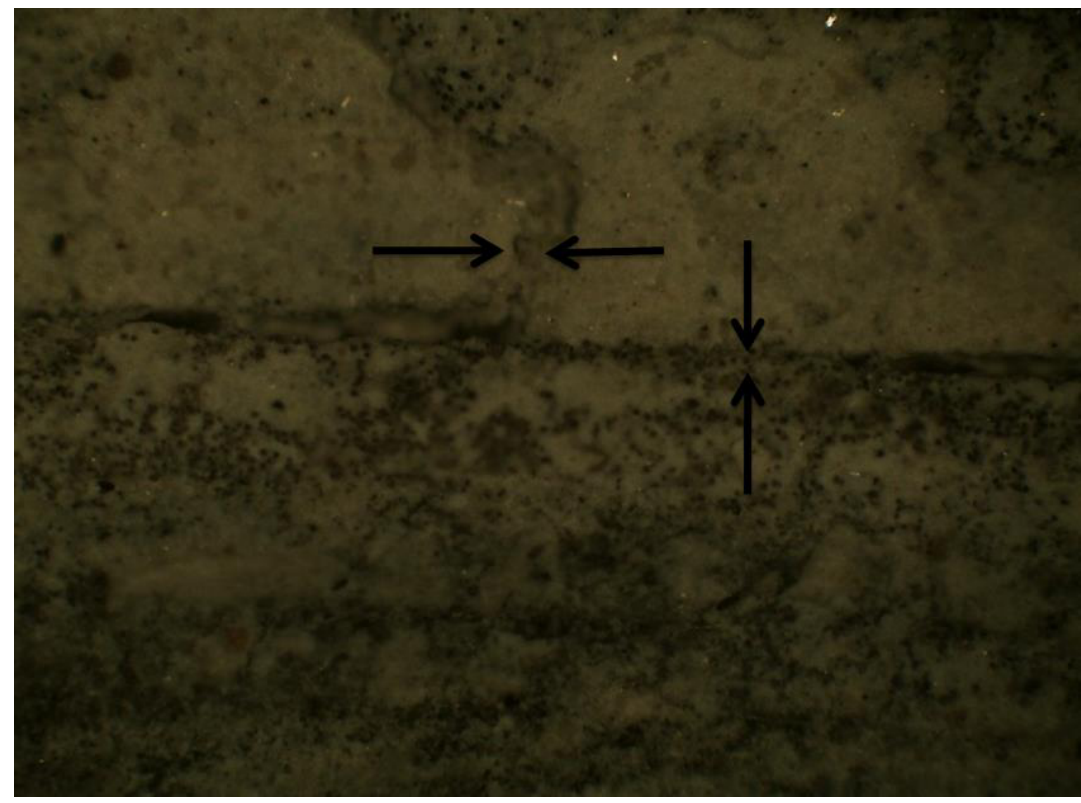

Fig. 5(b). The optical microscope image between kaolin geopolymer coating and GRE pipe sample after flexural testing

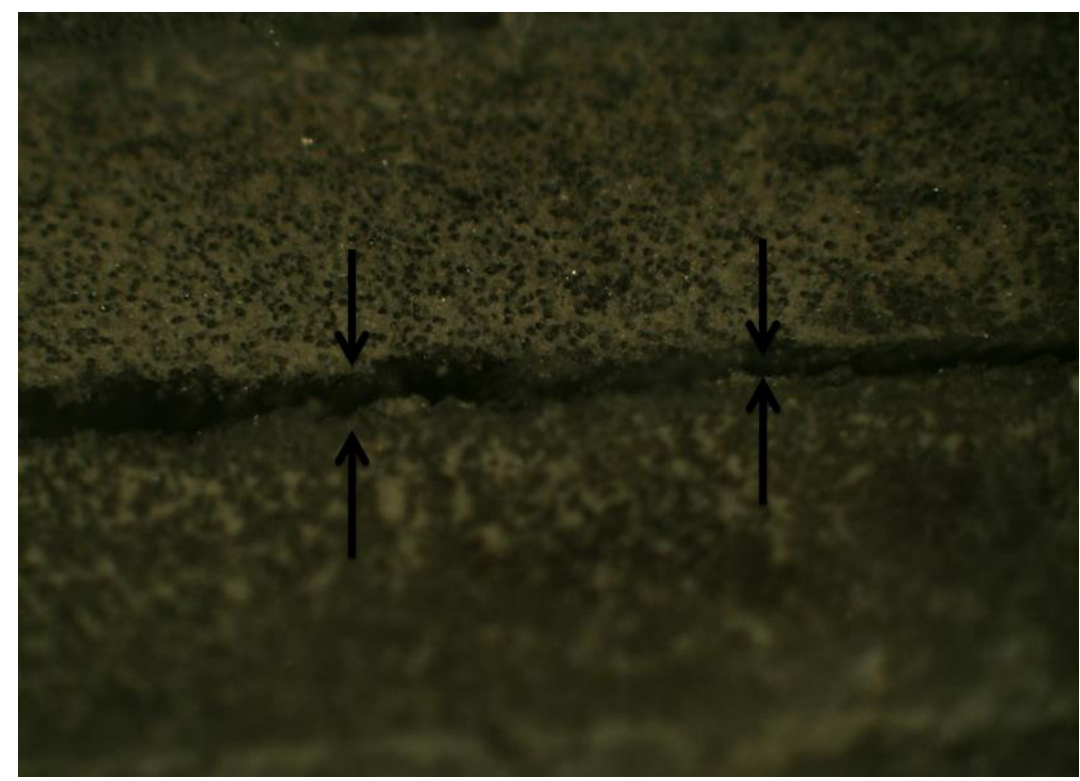

Fig. 5(c). The optical microscope image between white clay geopolymer coating and GRE pipe sample after flexural testing 


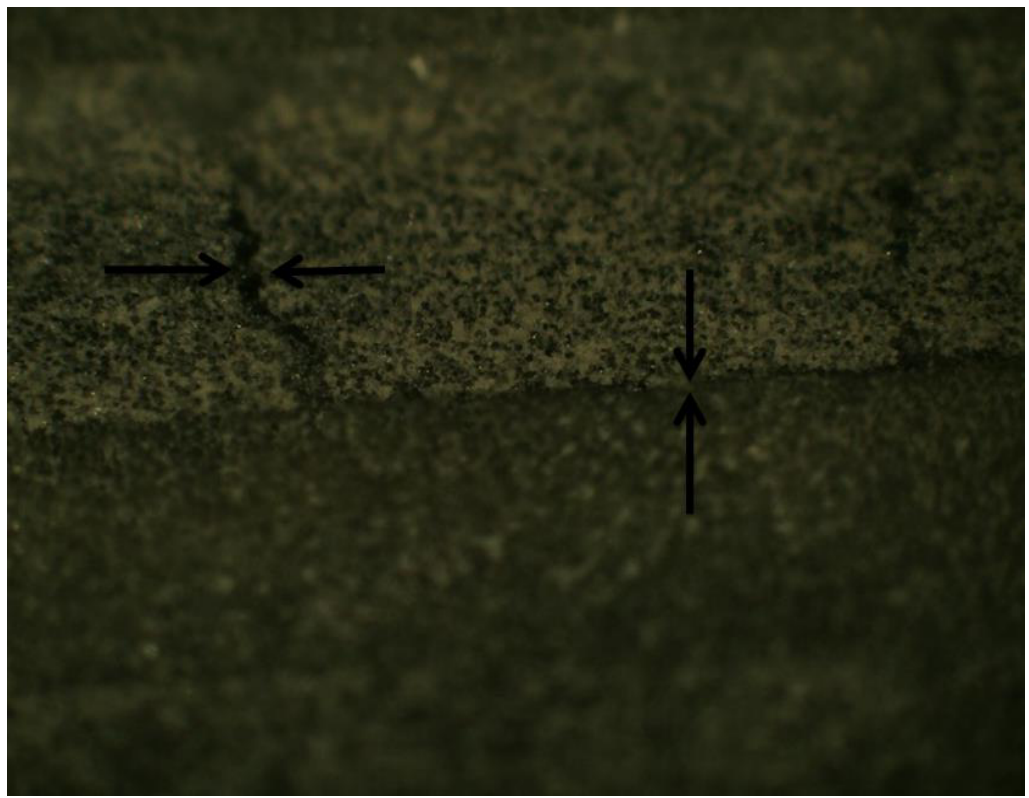

Fig. 5(d). The optical microscope image between silica sand geopolymer coating and GRE pipe sample after flexural testing

\section{Summary}

As conclusion, the $\mathrm{Na}_{2} \mathrm{SiO}_{3} / \mathrm{NaOH}$ ratio play importance role in the mix design for geopolymer coating form rigid final product, improve mechanical properties and formed better interfacial in geopolymer coating. However, different source materials gave different microstructure and property in geopolymer coating.

This work is supported by Centre of Excellence Geopolymer System Research @UniMAP. Also, the authors of the present work wish to dedicate their great thanks to KACST for funding this study through the collaboration between UniMAP-KACST.

\section{References}

1. J.G.S. Van Jaarsveld, J.S.J. Van Deventer, A. Schwartzman, Miner. Eng., 12, 75 (1999)

2. H. Xu, J.S.J. Van Deventer, Int. J. Miner. Process., 59, 247 (2000)

3. Y. He, X. Cui, X. Liu, Y. Wang, J. Zhang, K. Liu, J. Membr. Sci., 447, 66 (2013)

4. J.H. Zhang, Mater. Lett., 116, 167 (2014)

5. Z. Zhang, K. Wang, B. Mo, X. Li, X. Cui, Energy Build., 87, 220 (2015)

6. J. Davidovits, J. Therm. Anal., 37, 1633 (1991)

7. J. Davidovits, Geopolymer Chemistry and Applications 2 nd edition (Geopolymer Institute, 2008)

8. A. Palomo, M. W. Grutzeck, M.T. Blanco, Cem. Concr. Res., 29, 1323 (1999) 
9. P. Duxson, A. Fernandez Jimenez, J. Provis, G. C. Lukey, A. Palomo, J. S. J. Van Deventer, J. Mater. Sci., 42, 2917 (2007)

10. T. Bakharev, Cem. Concr. Res., 35, 1224 (2005)

11. A. Fernandez-Jimenez, A. Palomo, Woodhead publishing Limited and CRC Press LLC, 167 (2009)

12. Z. Zhang, X. Yao, H. Zhu, Appl. Clay Sci., 49, 1 (2010)

13. Z. Zhang, X. Yao, H. Zhu, Appl. Clay Sci., 49, 7 (2010)

14. G. Bierwagen, D. Tallman, Prog. Org. Coat., 41, 201 (2001)

15. P. Balaguru, Stephen Kurtz, and Jon Rudolph, Geopolymer for repair and rehabilitation of reinforced concrete beams (St Quentin, France, Geopolymer Institute, France, 1997)

16. H.F. Liu, X.M. Cui, W.P. Zhang, W.G. Hua, S.H. Qiu, Rare. Metal. Mat. Eng., 341 (2008)

17. X.F. Li, X.M. Cui, S.D. Liu, B.H. Mo, L. Cui, Key Eng. Mater., 537, 261 (2013)

18. J. Temuujin, A. Minjigmaa, W. Rickard, M. Lee, I. Williams, A. Van Riessen, Appl. Clay Sci., 46, 265 (2009)

19. J. Temuujin, A. Minjigmaa, W. Rickard, M. Lee, I. Williams, A. Van Riessen, J. Hazard. Mater., 180, 748 (2010)

20. A. M. Mustafa Al Bakri, H. Kamarudin, M. Bnhussain, I. Khairul Nizar, W. I. W. Mastura, Journal of Asian Scientific Research, 1, 247 (2011)

21. A. M. Mohd Mustafa Al Bakr, J. Liyana, H. Kamarudin, H. Mohammad, C. M. G. Ruzaidi C, A. Izzat, Adv. Mat. Res., 686, 227 (2013)

22. D. Dutta, S. Thokchom, P. Ghosh, S. Ghosh, J. Eng. Appl. Sci., 5, 74 (2010)

23. H. Xu, J. S. J. Van Deventer, G. C. Lukey, Industrial \& Engineering Chemistry Research, 40, 3749 (2001)

24. E. Douglas E., A. Bilodeau, J. Brandsterr, Cem. Concr. Res., 21, 101 (1991)

25. C.Y. Heah, H. Kamarudin, A.M. Mustafa Al Bakri, M. Binhussain, M. Luqman, I. Khairul Nizar, Y.M. Liew, Constr. Build. Mater., 35, 912 (2012)

26. K. Komnitsas, D. Zaharaki, Miner. Eng. 20, 1261 (2007)

27. L. Huggenberger, A. Manfred, H. H. Köster, Pigment Coating and Surface Sizing of Paper (Fapet Oy, Jyvaskyla, 2000)

28. Y.M. Liew, H. Kamarudin, A.M.M. Al Bakri, M. Bnhussain, M. Luqman, I. Khairul Nizar, C.M. Ruzaidi, C.Y. Heah, Phys. Procedia., 22, 312 (2011)

29. R.A. Fletcher, K.J.D. MacKenzie, C.L. Nicholson, S. Shimada, J. Eur. Ceram. Soc., 25, 1471 (2005)

30. J. Davidovits, First international conference on alkaline cements and concretes, 1, 131 (1994) 